\title{
The Preference of Direct or Indirect Methods in Preparing the Statement of Cash Flows in Decision Making: An Academic Perspective
}

\author{
Abdullah, S. Hardan ${ }^{1}$, Majed, A. Qabajeh ${ }^{2} \&$ Aymen, M. Alshanti ${ }^{3}$ \\ ${ }^{1}$ Applied Science Private University, Amman, Jordan \\ ${ }^{2}$ Petra University, Jordan \\ ${ }^{3}$ Al- Balka Applied University, Jordan \\ Correspondence: Abdullah, S. Hardan, Applied Science Private University, Amman, Jordan. E-mail: \\ a_hardan@asu.edu.jo
}

Received: November 25, 2015

Accepted: December 7, $2015 \quad$ Online Published: January 25, 2016

doi:10.5539/ijef.v8n2p206

URL: http://dx.doi.org/10.5539/ijef.v8n2p206

\begin{abstract}
Two methods are used when reporting cash flows from operating activities: the direct method or the indirect method, both are acceptable from IAS with a preference of direct method. Thus, this paper examines which method of reporting the statement of cash flows provides useful information the decision makers rely on for decision making purposes. To achieve this aim, participants were selected from academic sector represented by universities professors. The study is based on the conceptual framework: qualitative characteristics of accounting information. To be useful, information must be relevant and represents faithfully what it claims to represent. In order to distinguish more useful financial information from those less useful, enhancing qualitative characteristics were examined. Results show that academic professors provide support for direct method of reporting cash flows over indirect method. The study sought to determine the effect of academic rank on these results. Evidence reveals that full and associate professors endorsed the preference of direct method more than assistant professors and lecturers. These results recommend the legislative bodies and entities to adopt the direct method in preparation the statement of cash flows.
\end{abstract}

Keywords: direct method, indirect method, qualitative characteristics, statement of cash flows

\section{Introduction}

Financial statements aim to provide financial information about entities that is useful to a wide range of users in making decisions. These statements are based on accrual basis which does not reflect cash flows as required, while users are concerned with changes in cash inflows and cash outflows, and the extent of success or failure of operating activities. According to that, the International Accounting Standard Board adopted IAS No. (7) entitled: The statement of cash flows, which provides information about cash receipt and cash payments during a period. The statement requires entities to analyze cash flows into three sections: operating, investing and financing activities. Reporting cash flows from operating activities can be presented using one of two methods: direct or indirect. These methods have an impact on the importance and the relevance of the information provided by the statement of cash flows to decision makers. The financial reporting is useful for decision-making if it includes information that is relevant, represented faithfully and enhancing qualities. Jordan as a developing country that is seeking to enter into the global economy adapted international accounting standards when issued the securities commission law no. 76/2002 and the decision of the board of commissioners of the securities commission no. 257/2005. Accordingly, Jordanian law allows entities to choose between direct or indirect method. This research will identify which method of reporting cash flows from operating: direct or indirect method is preferred for decision-making from academic sector point of view in Jordanian universities, in order to encourage applying the method which provides qualitative information supporting decision-making according to the result of this research. One of the justifications is that the researches in this field at local level are rare. Besides, this study is the first one-according to our knowledge-that explores academics' point of view about the method preferred. Prior researches examine the usefulness of direct method versus indirect method to the users and the incentives motivating to choose the direct method over the indirect method; the results of Zhao and El- Masry (2013), 
Orpurt and Zang (2009), Kojima (2012), Goyal (2004), Hassan and Christopher (2001), refer to preferences of direct method compared to indirect method.

The rest of this paper is organized as follows: Section 2 reviews the importance of cash flow statement and qualitative characteristics of accounting information. Section 3 provides the literature review. Section 4 contains research design and methodology adopted. Section 5 explains and analyzes the results of the hypotheses. Finally, section 6 reports conclusions, limitations and future research.

\section{Statement of Cash Flows and Qualitative Characteristics of Accounting Information}

Net income figure, which is prepared on accrual basis, tainted by ambiguity and lack of clarity due to the estimates used such as depreciation, amortization and accruals. Net income does not reflect the cash flows, whereas cash flows statement does, and its information became an important element in financial decisions. The statement shows the monetary impact of all activities undertaken by the entities during the financial period with clarifying the nature of that impact whether cash inflows or cash outflows. The statement provides relevant information that explains in detail the changes that occurred to cash and cash equivalent, and how the firm generates and spends cash during a period. It gives managers, equity analysts, commercial lenders, and investment bankers a thorough explanation of the changes that occurred in the firms cash balance, Gibson (2007). It enables users of financial statements to estimate the amounts, timing, and uncertainty of future cash flows, and to evaluate financial flexibility of the entity. Cash flows provide information to help the users assess the entities ability to meet its obligations when due, to pay dividends, meet the cash needs of operational activities, and assess the risk of credit facilities to customers (financial institutions). The statement permits users to compare performance of various entities, regardless of the nature of the business activities and its geographic locations. Despite all of those advantages, cash basis is suffering from matching revenues and expenses.

Cash flows are classified and reported according to three activities: operating, investing and financing activities. After summarizing cash receipts and cash payments within each of the three groups, offset is done between the cash changes of items in each group in order to achieve net cash flow. IAS 7 defined each of these three categories: operating activities are revenues that are produced from normal entities activities, while acquisition of long-term assets and disposal is the so considered investing activities. Finally, financing activities occurred from the changes in equity and borrowings.

Cash flows from operating activities reflect the ability of businesses to generate cash flows and paid cash outflows; the more net cash flows indicate the entities ability to meet operational commitments. In order to identify cash inflows and outflows, two approaches are presented: direct method and indirect method. The difference between the two methods is restricted to the measurement of cash flows related to operating activities, cash flows associated with investment and financing activities do not vary according to the preparation methods, hence whether we use either two methods when preparing cash flows from investment and financing activities, the result is the same. International accounting standards explain these two approaches: Under direct method cash receipts (such as cash receipts from sale of goods or rendering services) and cash payments (such as cash payments to suppliers for the purchase of goods and for employees), both are disclosed separately, Orpurt and Zang (2009) demonstrated that direct method provides information which may be useful in estimating future cash flows and future earnings. According to Jones et al. (1995), Kojima (2012), Widjaja (1998), direct method is better for understanding cash flow data. Jones et al. (1995) found that direct method facilitates cash flow analysis, and is a better indicator of company solvency.

Indirect method is based on the adjusted net income elements to get net cash flows. In this way, the starting point is to start accounting profit number extracted from income statement which is prepared according to the accrual basis in the measurement of revenue and expenses. Profit or loss is adjusted by non-cash items such as depreciation and amortization. Thereafter, net income is adjusted by changes of items such as accounts receivables, inventories, accounts payables and accruals. However, indirect method provides less information in comparison with direct method because indirect method doesn't disclose cash inflows and outflows from operating activities individually. Although both methods are acceptable, but IAS implicitly encourages entities using direct method. Minority of firms voluntarily report direct method, while the majority preferred indirect method . Bahnson et al. (1996) report that $97.5 \%$ of the sample companies in the 1991 Accounting Trends and Techniques publication used the indirect method alone (AICPA, 1992). However, in contrast to these evidences, Bond et al (2012) found that a minority changed their reporting from direct to indirect method.

The quality of any decision made is based on the quality of accounting information provided by financial reports. To achieve the increased interest in obtaining useful information in order to help users for decision making, IAS issued the qualitative characteristics (QCs) of useful financial reporting as set out in the 
conceptual framework. Goyal ( 2004 ) study is related to the conceptual framework, precisely relevance and reliability. Qualitative characteristics consist of fundamental qualitative characteristics and enhancing qualitative characteristics. Relevant and represents faithfully are the fundamental qualitative characteristics which distinguish useful financial reporting information from that is not useful or misleading. While financial information that is relevant and faithfully represented is enhanced if that information is comparable, verifiable, timely and understandable.

Information is relevant to users of financial statements if it is capable of making a difference in the decisions made. QC7 mentioned that financial information is capable of making a difference in decisions if it has a predictive value, confirmatory value, or both. QC12 explains the need to represent information faithfully: to be useful, financial information must not only be relevant, but must also faithfully represents the phenomena that it purports to represent. Hence, these characteristics focus on substance rather than the form. To be perfectly faithful representative, accounting information should be complete, neutral, and free from error.

Enhancing financial information will help the users to better understand firms' performance. Qualitative characteristics that enhance the usefulness of information are: comparability, verifiability, timeliness and understandability.

\section{Literature Review}

Several studies have addressed the usefulness of direct method comparing to indirect method for decision making purposes:

Orpurt and Zang (2009) explored the predictive value of direct method cash flow disclosures of 119 U.S. firms over the period from 1989 to 2002 with a larger sample totaled 39,255 firm-year observations. They concluded that firms producing direct method statements have more valuable information about future cash flows and earnings reflected in their current stock returns than firms producing only indirect method statements. One of the early studies concerning predicting future operating cash flows is Krishnan and Largay (2000). Using 405 U.S firm observations reporting direct method for period from 1988-1993, they examined the predictive ability of direct method versus indirect method. They concluded that direct method information is more valuable for forecasting future cash flows. Zhao and El-Masry (2013) results from 217 firms issuing direct method cash flows statement during the period 1989-2009, that information provided from direct method is more useful in accuracy of analysts' future cash flows predicts than indirect method.

Hassan and Christopher (2001) argued in their study incentives motivating Malaysian firms to voluntarily choose the direct method over the indirect method in reporting cash flow from operating activities in their 1997 annual financial reports. The study, which consists of 231 firms, hypothesized that such decision is influenced by the signaling perspective. Results reveal that the preference of direct method is influenced by management efficiency, firms' size, and its auditor. Kojima (2012) conducted a study to examine whether the two methods of presenting financial reports influences the lending decisions made by their users. Less experienced users of financial statements, namely: thirty-eight accounting students (graduates and undergraduates) participated, rather than professionals, given a research instrument that tests decision making based on two different presentations of the statement of cash flows. The results suggest that presentation format influences users' decision making, and the direct method of presentation (partly because it does not require additional calculation needed as under the indirect method of presentation to calculate operating cash flow information) is the preferred method to use because of such advantages. Bond et al. (2012) noted that minority of entities selected to switch their reporting from direct to indirect, while the majority of Australian firms retained direct method when disclosing cash flows. Jones and Widjaja (1998) asked 159 financial statement users in Australia 115 questions about the relevance of the statement of cash flows, and the relevance of direct method versus indirect method information for the decision making. Findings reveal that direct method is more understandable and useful for decision making than the indirect method. Jones et al. (1995) focused on internal instead of external (preparers rather than users); they surveyed 210 Australian public companies. The survey indicated that a majority of respondents preferred the direct method, because it helped users to understand the cash flow data, facilitated cash flow analysis, and is a better indicator of company solvency.

Goyal (2004) surveyed bankers, managers, shareholders, employees, suppliers, and customers with 47 responses, in order to identify their perceptions of which reporting method is more useful for users of financial reports. Overall results prove the superiority of the direct method. In details, managers and shareholders respond that the direct method is relevant and reliable, while a majority of employees and customers had neutral feelings towards the relevance and reliability of either the direct or indirect methods. Clinch et al. (2002) investigated the usefulness of direct and indirect cash flow disclosures to explain annual returns for 350 Australian firms during 
1992-1997. The results indicate that components of operating cash flow have incremental explanatory power for market returns over aggregate operating cash flows for both industrial and mining companies when they also have significant incremental predictive ability for future (one year ahead) operating cash flows. They found a strong association between direct method of cash flow reporting and return on equity.

The literature review demonstrates that direct method is more understandable than indirect method, more useful in predicting future cash flows and performance. Presentation of direct method is straightforward and easy.

\section{Research Design}

The construction of the methodology adopted consists of questions, hypotheses, data and sample Selection.

\subsection{Questions and Hypothesis}

The differentiation between the methods: direct and indirect, results from information content quality, so this paper seeks to extend prior research concerning the preference of direct or indirect methods based on the qualitative characteristics of accounting information in decision making within the Jordanian context. The research questions derived from research issues are:

First question: Which of the two methods direct or indirect contains information that is more relevant to decision-making?

Secondly: Which of the two methods direct or indirect faithfully represents information and can be dependent upon?

Third question: In which of the two methods direct or indirect the qualitative characteristics that improve the usefulness of financial information are more enhanced?

Three hypotheses were developed to answer the research questions are as follows:

H1: Direct method information is not relevant to decision making as the indirect method.

H2: Direct method does not represent information faithfully, hence it is less useful to decision making than the indirect method.

H3: Direct method information is not enhanced and cannot be depended upon as the indirect method.

\subsection{Data and Sample Selection}

In order to gather relevant information, the study surveyed Jordanian universities. Participants were selected from academic sector who have the education and knowledge, experience and understanding of cash flows statement. The sample included sixty one lecturers in accounting departments from four Jordanian universities. We ended up with a sample of thirty eight lecturers as follows: eighteen sample from Applied Science University, five from Philadelphia University, six from Petra University, and nine sample from Al-Balka Applied University.

\subsection{The Survey}

Based on academic research, following Hales and Orpurt (2013), Koji Kojima (2012), Goyal (2004), Jones and Widjaja (1998), and Jones et al. (1995); we conducted a questionnaire designed based on the conceptual framework: qualitative characteristics of accounting information. The subjects were asked to rate their responses on a five-point Likert scale, where rating scale 5: strongly agree, 4: agree, 3: neutral, 2: disagree, 1: strongly disagree. The survey instrument was grouped into two sections: First section consisted of demographic questions: e.g., age, academic experience, and academic rank. Second section encompassed thirty eight questions regarding qualitative characteristics of accounting information. These questions were grouped into three sections in order to identify which method of reporting cash flows from operating provides relevant, represented faithfully, and enhancing qualities information for decision-making.

\section{Analysis and Discussion}

\subsection{Reliability of Instrument}

The study used a questionnaire, and in order to assess the degree of the reliability, cronbach alpha was used. It measures the internal consistency of questions in a survey instrument. Its value ranges from 0 to 1 . The higher the score, the more reliable the generated scale is. Nunnaly (1978) has indicated 0.7 and up for good internal consistency. The questionnaire achieved 0.876 score, which indicates a high level of internal consistency for our instrument. That means the questions in the instrument implied what is intended to ask, namely identify which method of reporting cash flows from operating, direct method or indirect method provides relevant, represented faithfully, enhancing qualities information for decision-making. 


\subsection{Descriptive Statistics}

Correlation coefficients used to measure how strong a relationship is between the demographic variables: age, gender, experience and rank. The demographic questions in the research instrument presented in table 1 provides descriptive statistics about the participants.

Table 1 . The demographic variables

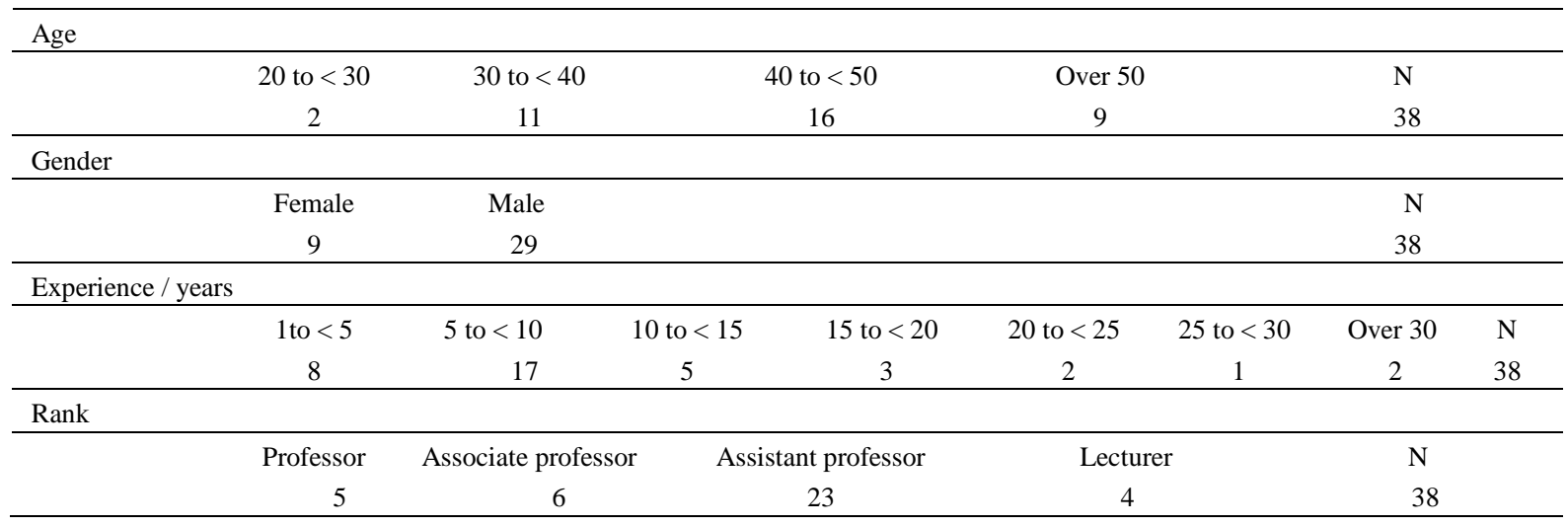

Table 1 shows that approximately three quarters of the participants were males, nearly $66 \%$ of the sample are over 40 years old, $88 \%$ of them with greater years of experience in their academic occupation. Full and associate professors were $29 \%$, the remainders $60.5 \%$ are assistant professors and $10.5 \%$ are lecturers. These variables were tested in order to determine if any meaningful correlations existed between them and to find out the impact of these variables upon the answers of the respondents. Table 2 summarizes the correlations between these variables.

Table 2. Correlations between demographic variables

\begin{tabular}{lcccc}
\hline & Age & Gender & Experience & Rank \\
\hline Age Correlation coefficient & 1 & 0.263 & 0.525 & $-0.484-$ \\
Sig. (2-tailed) & & 0.111 & 0.001 & 0.002 \\
N & 38 & 38 & 38 & 38 \\
Gender Correlation coefficient & 0.263 & 1 & 0.252 & $-0.435-$ \\
Sig. (2-tailed) & 0.111 & & 0.126 & 0.006 \\
N & 38 & 38 & 38 & 38 \\
Experience Correlation coefficient & 0.525 & 0.252 & 1 & $-0.616-$ \\
Sig. (2-tailed) & 0.001 & 0.126 & & 0.000 \\
N & 38 & 38 & 38 & 38 \\
Rank Correlation coefficient & $-0.484-$ & $-0.435-$ & $-0.616-$ & 1 \\
Sig. (2-tailed) & 0.002 & 0.006 & 0.000 & 38 \\
N & 38 & 38 & & 38 \\
\hline
\end{tabular}

Note. correlation is significant at the 0.01 level (2-tailed).

Table 2 shows that most of these variables are found to be correlated. The demographic variables: age, experience and rank have an impact on the academic member's opinion. Age was significant with academic experience and with academic rank; whereas gender was insignificant. To explain the negative correlation between age and rank, we find that approximately $68 \%$ of the sample over 40 years were assistant professors, in other words, the high percentage of sample who have lower rank were older in age. Experience is significant with rank, as a whole, the percentage of those who have more than 5 years' academic experience approached $80 \%, 37 \%$ out of them were full and associate professors, while the remaining percent represents the majority which consists of assistant professors and lecturers. This explains the inverse correlation between rank and experience.

These results revealed that the age of respondents with sufficient experience and academic ranks have an impact 
effect on the respondents' opinion regardless of being male or female, the results showed the absence of differences between the samples due to gender. We noted from these results the effect of the majority of sample represented in assistant professors and lecturers on the findings, so later the influence of academic rank on the opinion of the respondents will be discussed.

\subsection{The Relevance of Direct vs. Indirect Method}

Three descriptive statistics were used: mean, median and standard deviation to verify the academic preference toward two methods. Table 3, presents the results for the variables used to measure the relevance of financial information.

Table 3. Descriptive statistics for the relevance of direct method or indirect method

\begin{tabular}{llcccc}
\hline & Mean & Median & Std. & Deviation & $\mathrm{N}$ \\
\hline Relevance & 3.42 & 3.44 & 0.76 & 38 \\
\hline
\end{tabular}

Note. 5: strongly agree, 4: agree, 3 : neutral, 2: disagree, 1 : strongly disagree.

Higher mean and median indicate higher level of direct method preferences.

The mean and median for direct method are 3.42 percent and 3.44 percent, respectively, with standard deviation 0.76 . These results revealed that the majority believed that direct method provides more useful information than indirect; it is more relevance to future predictions, and confirming or changing previous evaluation, but it must be taken into account that only a small majority of professors believe that the relevance of direct method is superior to the indirect method, to some extent their responses are close to agreement.

\subsection{Faithfulness of Represented Direct or Indirect Method}

Faithful representation was also measured. Table 4, presents three descriptive statistics used: mean, median and standard deviation to measure the extent of representing information faithfully direct or indirect:

Table 4. Descriptive statistics for the faithfulness of represented direct or indirect method

\begin{tabular}{lccccc}
\hline & Mean & Median & Std. & Deviation & $\mathrm{N}$ \\
\hline Represented faithfully & 3.46 & 3.50 & 0.53 & 38 & \\
\hline
\end{tabular}

Note. 5: strongly agree, 4: agree, 3: neutral, 2: disagree, 1: strongly disagree.

Higher mean and median indicate higher level of direct method preferences.

The standard deviation for direct method is 0.53 with mean and median 3.46 percent and 3.50 percent, respectively. The results suggest that direct method involves information that is complete, whereas all information that is necessary for users is included. Direct method is neutral and unbiased in the selection or presenting the information. In addition, information provided is free from material error or omissions. Professors believed that the faithfulness represented by direct method is more than indirect, hence we can depend upon. But with caution to the result which reveals a small majority that endorses the superiority of direct method to the indirect method, with a scale closer to agree.

\subsection{Enhancing Financial Information}

The enhancing qualitative characteristics were measured, and Table 5, presents descriptive statistics for the variables that enhance the usefulness of information.

Table 5. Descriptive statistics for enhancing financial information

\begin{tabular}{lcccc}
\hline & Mean & Median & Std. Deviation & N \\
\hline Enhancing qualities & 3.40 & 3.46 & 0.67 & 38 \\
\hline
\end{tabular}

Note. 5: strongly agree, 4: agree, 3: neutral, 2: disagree, 1: strongly disagree.

Higher mean and median indicate higher level of direct method preferences.

The mean and median are 3.40 percent and 3.46 percent, respectively, with standard deviation 0.67 for direct method. This means that direct method contains useful information that can be depended upon more than indirect 
method. Financial information is comparable; hence its usefulness is enhanced. Comparability enables users to identify and recognize the differences and similarities because information measured and reported in a similar manner. Direct method information is verifiable, available in time to decision maker and understandable. Financial information is classified, characterized and presented clearly. Once again there is a minute difference between those who prefer direct method and those who do not.

\subsection{Academic Ranks}

Previous results do not explain the impact of academic ranks on the choice of respondents in preferring either of the two methods. Hence, next step is to display the role of having a higher or lower academic rank, namely professors, associate professors, assistant professors and lecturers, in tipping the direct method, table 6 is set as follows:

Table 6. Academic rank impact on the preference of direct method

\begin{tabular}{lcccc}
\hline & Mean & Median & Std. Deviation & $\mathrm{N}$ \\
\hline Professors: & & & & 5 \\
\hline Relevance & 3.68 & 3.76 & 0.36 & 0.35 \\
Represented faithfully & 3.72 & 3.87 & 0.60 & 6 \\
Enhancing qualities & 3.64 & 3.92 & & 0.37 \\
\hline Associate professors: & & & 0.31 & \\
\hline Relevance & 3.67 & 3.70 & 0.30 & \\
Represented faithfully & 3.80 & 3.75 & & \\
Enhancing qualities & 3.49 & 3.38 & 0.91 & \\
\hline Assistance professors: & & & 0.57 & \\
\hline Relevance & 3.38 & 3.23 & 0.76 & \\
Represented faithfully & 3.41 & 3.25 & & \\
Enhancing qualities & 3.37 & 3.46 & 0.49 & \\
\hline Lecturers: & & & 0.43 & \\
\hline Relevance & 3.16 & 2.87 & & \\
Represented faithfully & 3.00 & 2.77 & & \\
Enhancing qualities & 3.00 & & & \\
\hline
\end{tabular}

Note. 5: strongly agree, 4: agree, 3: neutral, 2: disagree, 1: strongly disagree.

Higher mean and median indicate higher level of direct method preferences.

Results from Table 6 show that professors and associate professors supported direct method, while assistant professors were less supportive of it, then finally came lecturers. These results prove that professors and associate professors, who have in-depth knowledge and experience about the quality of the financial information provided, endorsed the preference of IAS for reporting cash flows from operating activities in direct form. The percentage of professors and associate professors composed about $30 \%$ of the sample which is considered a marked factor affecting the findings in comparison with number of assistant professors and lecturers who formed a higher percent, and that in turn explains the differences between statistical results as a whole (exhibited in table 3,4and 5) and the latest one listed in Table 6.

\section{Conclusions, Limitation and Future Research}

Based on academic experience of the universities professors, their opinion was investigated about the preference of using direct or indirect methods in preparing the statement of cash flows in decision making. Three hypotheses were tested in order to answer the following questions: First question: Which of the two methods direct or indirect contains information that is more relevant to decision-making?

Second question: Which of the two methods direct or indirect faithfully represents information and can be dependent upon?

Third question: in which of the two methods direct or indirect the qualitative characteristics that improve the usefulness of financial information are more enhanced?

The evidence from the survey results revealed that the academics preferred the direct method of reporting cash flows, it is perceived as superior to the indirect method. Direct method provides more relevant information to users of financial statements regarding their predictions and confirming previous evaluation. Direct method 
contains complete information, neutral and free from error. This information is represents faithfully and can be depended upon. The qualitative characteristics that enhance the usefulness of information are: comparability, verifiability, timeliness and understandability, and the results suggest that direct method provides enhanced information. Professors and associate professors who possess in-depth knowledge and experience, supported direct method, while assistant professors and lecturers were less supportive of it. These results are consistent with IAS recommendation of using the direct method to present the statement of cash flows.To some extent these results are consistent with findings of Jones and Widjaja (1998), Goyal (2004) and Orpurt and Zang (2009). These results motivate and encourage the legislative bodies and entities to adopt the direct method in the preparation of the statement of cash flows.

Whilst this paper focused on academic sector with a small sample being surveyed, further researches is required on a wider scale and by incorporation of academics and professionals in order to clarify the differences between them. We also recommend practical studies to take part in this field.

\section{Acknowledgements}

The authors are grateful to the Applied Science Private University, Amman, Jordan, for the full financial support granted to this research project (DRGS-2014-2015-197).

\section{References}

Ahmed, K., \& Ali, M. (2013). Determinants and usefulness of analysts' cash flow forecasts: Evidence from Australia. International Journal of Accounting and Information Management, 21(1), 4-21. http://dx.doi.org/10.1108/18347641311299722

Ali, A. (1994). The Incremental information content of earnings, working capital from operations, and cash flows. Journal of Accounting Research, 32(1), 61-74. http://dx.doi.org/10.2307/2491387

Bahnson, P., Miller, P., \& Budge, B. (1996). Non articulation in cash flow statements and implications for education, research and practice. American Accounting Horizons, 10(4), 1-15

Bond, D., Bugeja, M., \& Czernkowski, R. (2012). Did Australian firms choose to switch to reporting operating cash flows using the indirect method? Australian Accounting Review, 60(22), 18-24. http://dx.doi.org/10.1111/j.1835-2561.2011.00156.x

Cheng, C., Liu, C., \& Schaefer, T. (1996). Earnings permanence and the incremental information content of cash flows from operations. Journal of Accounting Research, 34(1), 173-181. http://dx.doi.org/10.2307/2491338

Clinch, G., Sidhu, B., \& Sin, S. (2002). The usefulness of direct and indirect cash flow disclosures. Review of Accounting Studies, 7, 383-404. http://dx.doi.org/10.2139/ssrn.251957

Frino, A., \& Jones, S. (2005). The impact of mandated cash flow disclosure on bid-ask spreads. Journal of Business Finance \& Accounting, 32(7/8), 1373-1396. http://dx.doi.org/10.1111/j.0306-686X.2005.00632.x

Gibson, C. (2007). Financial reporting and analysis (10th ed.). Canada: Thomson.

Goyal, M. (2004). A Survey on popularity of the direct method of cash flow reporting. JAMAR, 2(2), 41-52.

Gunesh, R., \& Priscille, H. (2014). Users perception on cash flow reporting practices in Mauritius. Studies in Business and Economics, 9(3), 82-96.

Hales, J., \& Orpurt, S. (2013). A Review of academic research on the reporting of cash flows from operations. American Accounting Association, 27(3), 539-578. http://dx.doi.org/10.2308/acch-50498

Hassan, S., \& Christopher, T. (2007). Determinants of the choice of reporting the direct method or indirect method of cash flow from operating activities: Malaysian evidence. Journal of Financial Reporting \& Accounting, 5(1), 139-156. http://dx.doi.org/10.1108/19852510780001580

Hughes, M., Hoy, S., \& Andrew, B. (2010). Cash flows: The gap between reported and estimated operating cash flow elements. Australasian Accounting Business and Finance Journal, 4(1), 96-114.

IASB. (2010). The conceptual framework for financial reporting. London: International Accounting Standards Board. Retrieved from http://www.ifrs.org /News/Press

IASB. (2010). Cash flow statements. IAS7.

Jones, S., \& Widjaja, L. (1998). The decision relevance of cash-flow information: A note. Abacus, 34(2), 204-219. http://dx.doi.org/10.1111/1467-6281.00030

Jones, S., Romano, C., \& Smyrnios, K. (1995). An evaluation of the decision usefulness of cash flow statements 
by Australian reporting entities. Accounting and Business Research, 25(98), 115-129. http://dx.doi.org/10.1080/00014788.1995.9729934

Jordan Securities Commission law. (n. d.). Retrieved from http://www.jsc.gov.jo

Kieso, D., Weygand, J., \& Warfield, T. (2011). Intermediate accounting. USA: John Wiley \& Sons.

Kojima, K. (2012). Decision usefulness of cash flow information format-An experimental study. International Review of Business, 12(3), 23-44.

Krishnan, G., \& Largay, J. (2000). The predictive ability of direct method cash flow information. Journal of Business Finance \& Accounting, 27(1-2), 215-245. http://dx.doi.org/10.1111/1468-5957.00311

Melville, A. ( 2015). International Financial Reporting (5th ed). Person.

Mooi, T. (2007). Predicting future cash flows: Does cash flow have incremental information over accrual earnings? Malaysian Accounting Review, 6(2), 63-80.

Nobes, C., \& Stadler, C. (2014). The qualitative characteristics of financial information, and managers' accounting decisions: Evidence from IFRS policy changes. Retrieved from http://www.ifrs.org/IFRS

Nunnally, J. C. (1978). Psychometric theory (2nd ed.). New York, NY: McGraw-Hill.

Orpurt, S., \& Zang, Y. (2009). Do direct cash flow disclosures help predict future operating cash flows and earnings? The Accounting Review, 84(3), 893-935. http://dx.doi.org/10.2308/accr.2009.84.3.893

Zhao, L., \& El-Masry, H. (2013). Assessing the ability of the direct method format of the statement of cash flows to boost financial analysts judgment accuracy. The Journal of Human Resource and Adult Learning, 9(2), $1-7$.

\section{Copyrights}

Copyright for this article is retained by the author(s), with first publication rights granted to the journal.

This is an open-access article distributed under the terms and conditions of the Creative Commons Attribution license (http://creativecommons.org/licenses/by/3.0/). 